\title{
A process for producing lignin and volatile compounds from hydrolysis liquor
}

\author{
Tooran Khazraie1, Yiqian Zhang ${ }^{2}$, Dmitry Tarasov², Weijue Gao², Jacquelyn Price ${ }^{2,3}$, Nikolai DeMartini' \\ Leena Hupa ${ }^{1}$ and Pedram Fatehi ${ }^{2^{*}}$
}

\begin{abstract}
Background: Hot water hydrolysis process is commercially applied for treating wood chips prior to pulping or wood pellet production, while it produces hydrolysis liquor as a by-product. Since the hydrolysis liquor is dilute, the production of value-added materials from it would be challenging.

Results: In this study, acidification was proposed as a viable method to extract (1) furfural and acetic acid from hot water hydrolysis liquor and (2) lignin compounds from the liquor. The thermal properties of the precipitates made from the acidification of hydrolysis liquor confirmed the volatile characteristics of precipitates. Membrane dialysis was effective in removing inorganic salts associated with lignin compounds. The purified lignin compounds had a glass transition temperature $(\mathrm{Tg})$ of $180-190^{\circ} \mathrm{C}$, and were thermally stable.
\end{abstract}

Conclusions: The results confirmed that lignin compounds present in hot water hydrolysis liquor had different characteristics. The acidification of hydrolysis liquor primarily removed the volatile compounds from hydrolysis liquor. Based on these results, a process for producing purified lignin and precipitates of volatile compounds was proposed.

Keywords: Acidification, Hydrolysis, Lignin, Furfural, Biorefining

\section{Background}

The current low price of pulp products has significantly hampered the overall profitability of the pulping industry. Forest biorefinery has been considered as an option to revisit this industry. In forest biorefinery, energy or biomaterials are produced in addition to pulp products [1]. In a forest biorefining process, cellulose can be produced as dissolving pulp, while lignin and hemicelluloses are converted to other value-added products [1,2].

Hot water hydrolysis process is commercially used for extracting hemicelluloses from wood chips. It was reported that hydrolysis liquor contains hemicelluloses and some lignin that can be used in the production of value-added products [3]. Hot water hydrolysis process can be carried out prior to pulping process $[4,5]$ or in wet torrefaction process [6]. In both processes, the hydrolyzed wood chips are transferred to the next steps

\footnotetext{
*Correspondence: pfatehi@lakeheadu.ca

${ }^{2}$ Chemical Engineering Department, Lakehead University, 955 Oliver Road, Thunder Bay, ON P7B 5E1, Canada

Full list of author information is available at the end of the article
}

for producing dissolving pulp or wood pellets, while a large volume of hydrolysis liquor that contains dissolved hemicelluloses and lignin is treated as a waste [7].

It is well-known that the severity of hydrolysis conditions affects the removal of lignocelluloses from wood chips, as well as the properties of extracted hemicellulose and lignin [5], which implies that changing the hydrolysis process conditions allows for producing hydrolysis liquor with different properties and chemistries. The first objective of this work was to study the effect of hydrolysis conditions in extracting lignocelluloses from the wood chips.

The hydrolysis liquor can be used as fermentation intermediate for the production of xylitol and ethanol due to the presence of dissolved hemicelluloses in the hydrolysis liquor [8]. However, fermentation inhibitors, such as furfural, acetic acid, and lignin derivatives in the hydrolysis liquor would hamper the efficiency of the fermentation processes $[9,10]$. Lignin can also be used as fuel or in the production of phenols, for instance [11]. Presently, hemicellulose and lignin of the hydrolysis liquor cannot be economically utilized in the production 
of value-added products due to the dilute nature of the hydrolysis liquor. In the past, ultrafiltration was proposed for isolating hemicellulose and lignin from hydrolysis liquor $[12,13]$, which could be efficient in concentrating hydrolysis liquor. However, filter blockage and fouling should be considered as main operation challenges of this process [14-16]. Adsorption and flocculation can also be viable options for extracting hemicellulose and lignin from hydrolysis liquor, but the need for recovering adsorbents, the high price and/or sensitivity of flocculants to the chemistry of hydrolysis liquor may be major barriers in the implementation of adsorption or flocculation process at an industrial scale [17]. Acidification has been commercialized as LignoBoost and LignoForce technologies for extracting kraft lignin from black liquor of kraft pulping process $[18,19]$. Although some research results showed that acidification was efficient in extracting organics from hydrolysis liquor of kraft-based dissolving pulp production process [20-22], it is not clear what components were extracted via acidifying hydrolysis liquor and what properties the extracted components had. Since the literature results on the acidification process are not conclusive, the second objective of this work was to evaluate the effectiveness of acidification in extracting different components from a hydrolysis liquor.

In the present work, spruce wood chips were treated with hot water in a pulping digester and then the hydrolysis liquor was collected and characterized to specify the impact of acidification on the precipitation of organic compounds extracted from wood chips.

Subsequently, the thermal properties of the precipitates were investigated in order to identify the potential enduse applications for the precipitates. The main novelties of this work were as follows:(1) a detailed investigation on the efficiency of acidification in removing different organic components from hydrolysis liquor including volatile compounds and hydrolysis lignin, which would impact the properties of the precipitates and their enduse applications, and (2) the development of a process for producing hydrolysis lignin and precipitates made of volatile compounds.

\section{Methods}

\section{Materials}

Industrially produced spruce wood chips (with the moisture content of $37 \%$ ) were received from a mill located in northern Ontario, Canada. This wood species is commonly used in Finland and Canada for pulp and energy production purposes. Sodium hydroxide pellets, sodium sulfate (analytical grade), sodium sulfite (analytical grade), acetic anhydride, para-hydroxybenzoic acid, 2-chloro-4,4,5,5-tetramethyl-1,2,3-dioxaphospholane, 3 -(trimethylsilyl) propionic-2,2,3,3- $\mathrm{d}_{4}$ acid sodium salt
(TSP), chromium(III) acetylacetonate, deuteriochloroform $\left(\mathrm{CDCl}_{3}\right)$, anhydrous pyridine, hydrochloric acid (37\%, reagent grade), and sulfuric acid (98 wt\%) were received from Sigma Aldrich company. Cellulose acetate membrane dialysis with a molecular cut-off of $1000 \mathrm{~g} /$ mol was obtained from Wako Chemicals, Japan.

\section{Hot water hydrolysis treatment}

In this set of experiments, $300 \mathrm{~g}$ of wood chips was placed in a $2 \mathrm{~L}$ pulping digester, Greenwood, TX. The impact of liquid to solid (L/S) ratio in the autohydrolysis of softwood was studied in the past [23, 24]. Leppanen et al. conducted the autohydrolysis of Norway spruce with L/S ratio 15/1 [25]. In current work, due to the small size of the pulping digester $(2 \mathrm{~L})$, the $\mathrm{L} / \mathrm{S}$ ratio of $15 / 1$ generated hydrolysis liquor with undetectable organic compounds (as it would result in a small quantity of wood in the digester). Therefore, a liquid to wood ratio of 8 (on a dried basis) was selected in this analysis with adding deionized water to the digester. The heating rate of the hydrolysis treatment was adjusted to $4.5{ }^{\circ} \mathrm{C} / \mathrm{min}$ when the temperature of the digester was below $100{ }^{\circ} \mathrm{C}$ and to $2.5^{\circ} \mathrm{C} / \mathrm{min}$ when the temperature of the digester increased above $100{ }^{\circ} \mathrm{C}$. The liquor in the digester was circulated at the flow rate of $6 \mathrm{~L} / \mathrm{min}$. Furthermore, autohydrolysis was successfully applied to spruce wood chips in the temperature range of $100-240{ }^{\circ} \mathrm{C}$ and time of $100 \mathrm{~min}[24,25]$. Song et al. reported a significant lignin isolation in the temperature range of $160-180{ }^{\circ} \mathrm{C}[24$, 26]. In the current work, the hydrolysis treatment was conducted at 170,180 , or $190{ }^{\circ} \mathrm{C}$ for 15 or $45 \mathrm{~min}$, where the $\mathrm{pH}$ of hydrolysis liquor after the hydrolysis treatment (i.e., after experiment at room temperature) was 3.2-3.6.

Figure 1 shows the flow chart of the experimental procedure conducted in this work to produce hydrolysis liquor and the methods to analyze it. As seen, after hot water hydrolysis treatment, the hydrolysis liquor was collected from the digester and digester was made empty. The lignin of hydrolysis liquor was denoted as hydrolysis lignin. Acid-soluble lignin with different structures is extracted during hot water hydrolysis process [12, 15]. In hydrolysis liquor, some lignin components are very hydrophilic and are soluble under strong acidic conditions (e.g., $\mathrm{pH}$ of 2), but some others have more complex structures, and are probably more hydrophobic and thus less soluble under acidic conditions. Furthermore, Lawoko et al. [27] and Lappane [25] stated that lignin compounds in spruce formed lignin-carbohydrate complexes (LCC) [27]. Therefore, it is possible that lignin with different structures and LCC compounds were formed in the hydrolysis process. In the present study, it was noted that a part of lignin compounds adsorbed on the interior parts of the digester. To collect adsorbed lignin 


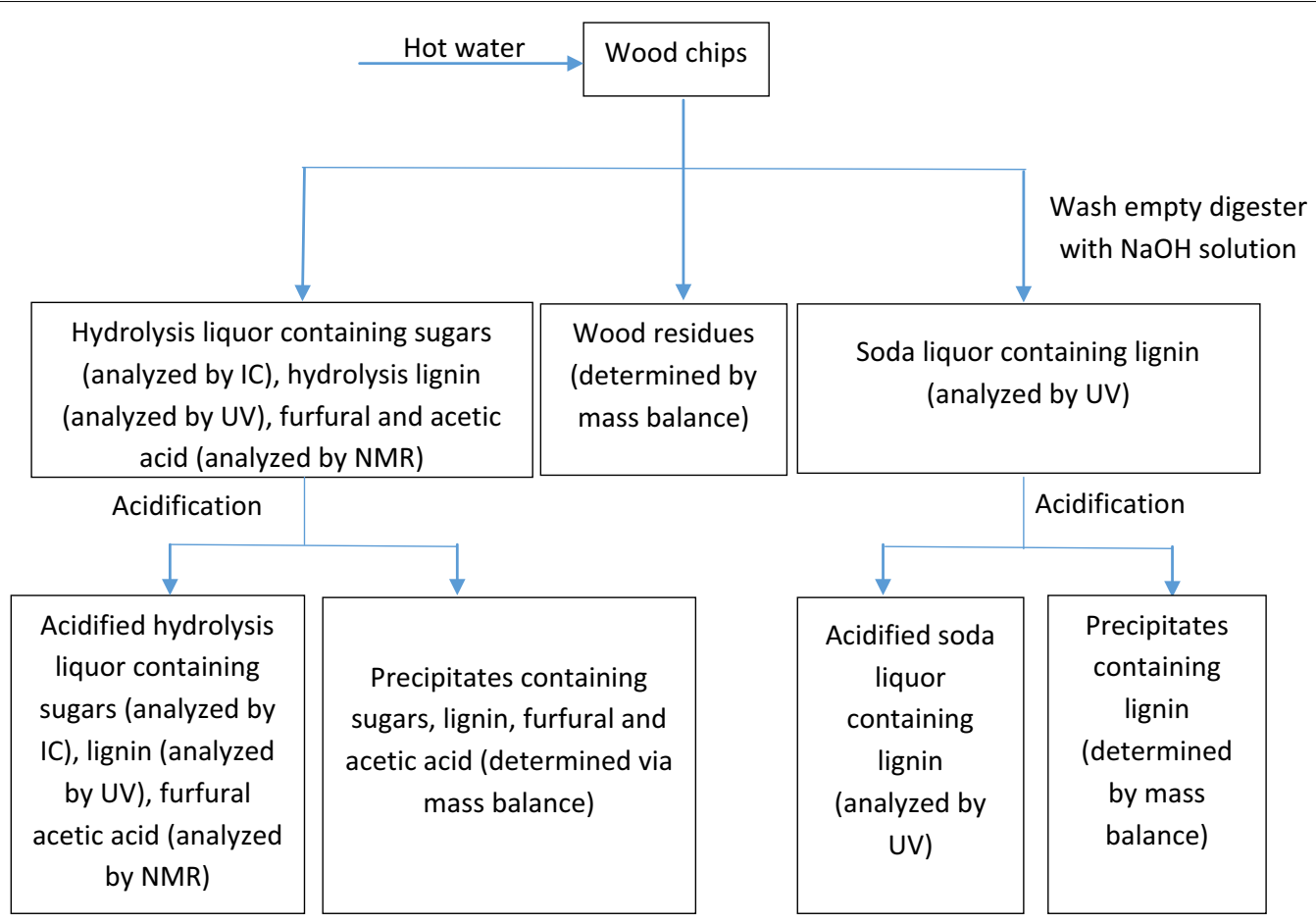

Fig. 1 Experimental procedure conducted for producing hydrolysis liquor and analytical methods followed for analyzing the products

from the interior surface of digester, the digester (after collection of treated wood chips and hydrolysis liquor) was treated with $1.5 \mathrm{~L}$ of $\mathrm{NaOH}$ solution (3 wt\%), which is donated as a soda liquor in this work. This soda treatment was repeated at different temperatures of 80 and $90{ }^{\circ} \mathrm{C}$ for $0.5,1$, and $1.5 \mathrm{~h}$ to collect the adsorbed lignin from the digester. The lignin dissolved in the soda liquor from treating the digester is denoted as soda liquor lignin in this work. The concentration of soda liquor lignin in the soda liquor was analyzed as stated in the following section. The treatment at $90{ }^{\circ} \mathrm{C}$ for $1 \mathrm{~h}$ generated a soda liquor with the highest lignin concentration. To ensure that no lignin had been remained in digester after soda liquor treatment, the treated digester was treated with fresh soda liquor solution as stated above, and the analysis confirmed negligible lignin in this solution. Therefore, the soda liquor treatment at $90{ }^{\circ} \mathrm{C}$ for $1 \mathrm{~h}$ with $3 \mathrm{wt} \%$ $\mathrm{NaOH}$ solution was selected as a method for extracting soda liquor lignin from the digester.

\section{Chemical composition analysis}

In this set of experiments, spruce wood chips were dried and then ground to a size smaller than $1 \mathrm{~mm}$ and then kept in a desiccator prior to analysis. In order to measure the hemicellulose and cellulose contents, the NREL method was applied to the ground wood particles [28]. The Klason lignin method was used to determine the contents of acid-soluble and acid-insoluble lignin of the ground wood particles (T 222 om-98 and UM 250). To determine the total content of extractives in spruce wood chips, they were treated with acetone/water $(95 / 5 \mathrm{v} / \mathrm{v})$ in Glas-Col Combo Mantle extraction apparatus for $6 \mathrm{~h}$. The final content of the extractives was determined using a gravimetric method.

\section{Sugar analysis}

The concentrations of polysugars and monosugars in the hydrolysis liquor and soda liquor were determined using ion chromatography, Dionex, ICS 5000, Thermofisher Scientific, equipped with CarboPac ${ }^{\mathrm{TM}}$ SA10 column and an electrochemical detector (ED) (Dionex-300, Dionex Corporation, Canada). Deionized water and $\mathrm{KOH}$ Eluent Generator (EGC $500 \mathrm{KOH}$, ThermoScientific) were used to generate an eluent of $1.00 \mathrm{mM}$ of $\mathrm{KOH}$ at a flow rate of $1.2 \mathrm{~mL} / \mathrm{min}$. The column temperature was set at $30{ }^{\circ} \mathrm{C}$. The monosugar concentration in the liquors was measured without pretreating the liquors but after adjusting $\mathrm{pH}$ of the liquors to 7 . The hydrolysis and soda liquors were acid-hydrolyzed under the conditions of $4 \%$ sulfuric acid at $121^{\circ} \mathrm{C}$ for $1 \mathrm{~h}$ in an oil bath (Hakke S45, Instruments, Inc., Portsmouth, N.H., USA) based on the method described in the literature [12]. This acid hydrolysis is widely used for converting oligosugars to monosugars [4, 12]. Afterward, the concentration of 
monosugars in the hydrolysis liquors was measured as stated above, and it reflected the concentration of total monosugars (after conversion of oligosugars to monosugars) in the hydrolysis and soda liquors. The concentrations of polysugars were determined via subtracting total sugar concentrations from monosugar concentrations.

\section{Lignin, furfural, and acetic acid analyses}

The lignin content of the liquors was determined according to TAPPI UM 250 using UV spectrophotometry at $205 \mathrm{~nm}$ (GENESYS 10S UV-Vis, Thermo Scientific) [12].

To measure the contents of furfural and acetic acid, the liquors were first dried. Then $0.4 \mathrm{wt} \%$ of 3-(trimethylsilyl) propionic-2,2,3,3- $\mathrm{d}_{4}$ acid sodium salt (TSP) in deuterium oxide $\left(\mathrm{D}_{2} \mathrm{O}\right)$ was prepared. About $40 \mathrm{mg}$ of dried liquor was added to $700 \mu \mathrm{L}$ of the $\mathrm{D}_{2} \mathrm{O}$ solution. After mixing the solution, it was transferred to the NMR vials. A proton nuclear magnetic resonance, NMR, Varian Unity Inova $500 \mathrm{MHz}$ spectrometer was used for determining the concentrations of furfural and acetic acid in the hydrolysis and soda liquors according to the previously established method [4].

\section{Molecular weight analysis of hydrolysis and soda liquors}

Samples with a $5 \mathrm{~g} / \mathrm{L}$ concentration in $0.1 \mathrm{~mol} / \mathrm{L} \mathrm{NaNO}_{3}$ were prepared from the hydrolysis and soda liquors, and then they were stirred at $300 \mathrm{rpm}$ for $24 \mathrm{~h}$. Then samples were filtered with a $0.2 \mu \mathrm{m}$ nylon filter $(13 \mathrm{~mm}$ diameter), and the filtered solutions were used for molecular weight analysis. The molecular weight of the samples was measured using a gel permeation chromatography, Malvern GPCmax VE2001 Module + Viscotek TDA305 with multi-detectors. The columns of PolyAnalytic PAA206 and PAA203 were used in the analysis, and a $0.1 \mathrm{mmol}$ $\mathrm{NaNO}_{3}$ solution was used as solvent and eluent. The flow rate was set at $0.70 \mathrm{~mL} / \mathrm{min}$, while the column temperature was $35{ }^{\circ} \mathrm{C}$ and poly (ethylene oxide) was used as a standard sample. The UV detector at $280 \mathrm{~nm}$ wavelength was used for determining the molecular weight of lignin, and IR detector was used for measuring the molecular weight of polysugars. This method was used for determining the molecular weight of lignin in the past [29].

\section{Acidification of hydrolysis and soda liquors}

Strong sulfuric acid treatment of hydrolysis liquor was followed as a method to separate hydrolysis lignin from hydrolysis liquor. The acidification at a high temperature is commercially used in the LignoForce technology to extract kraft lignin from black liquor [14]. To understand the efficiency of acidification process in isolating lignin from hydrolysis and soda liquors, the liquors were acidified with sulfuric acid ( $1 \mathrm{~mL}$ of $98 \mathrm{wt} \%$ in $900 \mathrm{~mL}$ liquor) to the $\mathrm{pH}$ of 1.5 (Fig. 1). The dilution factor caused by mixing acid with the liquors was considered in determining the concentration of organic compounds in the liquors. Then the mixtures were heated to $80{ }^{\circ} \mathrm{C}$ and kept for $15 \mathrm{~min}$ at $80^{\circ} \mathrm{C}$. The precipitates formed in hydrolysis and soda liquors were then separated via filtration/centrifugation (4000 rpm for $10 \mathrm{~min}$ ). The collected samples after centrifugation were analyzed comprehensively. A part of the collected precipitates of soda liquor was dialyzed for 2 days using membrane dialysis, while changing water every $4 \mathrm{~h}$ to remove impurity, and the properties of dialyzed samples were assessed.

\section{TGA and DSC analyses of precipitates}

The thermal characteristics of the precipitates made from hydrolysis and soda liquors were analyzed using a thermogravimetric analyzer (TGA) and differential scanning calorimeter (DSC). In this set of experiments, $8-12 \mathrm{mg}$ of dried precipitates were loaded in a platinum (Pt) crucible of a thermogravimetric analyzer (TGA)-i1000 series (Instrument Specialist Inc.) and heated isothermally at $100{ }^{\circ} \mathrm{C}$ for $10 \mathrm{~min}$ to ensure moisture removals. Then the samples were heated to $700{ }^{\circ} \mathrm{C}$ under nitrogen $(35 \mathrm{~mL} /$ min) with an increment rate of $10{ }^{\circ} \mathrm{C} / \mathrm{min}$.

Moreover, the thermal behavior of precipitates were investigated using a differential scanning calorimeter (DSC), TA instrument, Q2000, and the standard cell RC mode of DSC was also used for analysis. The samples were treated at $60^{\circ} \mathrm{C}$ in an oven for removing moisture, then $8-10 \mathrm{mg}$ of the dried samples were loaded into a Tzero aluminum pan, and analyzed by heat/cool/ heat method in a temperature range from 30 to $250{ }^{\circ} \mathrm{C}$ at $50 \mathrm{~mL} / \mathrm{min}$ in nitrogen. The heating and cooling rates were both controlled at $5{ }^{\circ} \mathrm{C} / \mathrm{min}$, and the second heating cycle (showed as exotherm up) was chosen for glass transition and melting point analyses.

\section{${ }^{31} \mathrm{P}$ NMR analysis of precipitates}

The $\mathrm{OH}$ functional groups of the precipitates were analyzed by quantitative phosphorous nuclear magnetic resonance $\left({ }^{31} \mathrm{P}\right.$ NMR) analysis. This process was carried out following a previously established procedure [30]. The precipitates were dried in a freeze drier overnight and a $36.6 \mathrm{mg}$ sample was added to $500 \mu \mathrm{L}$ of anhydrous pyridine/chloroform-d (1.6/1.0, v/v) solution. A $50 \mu \mathrm{L}$ of a pyridine/chloroform-d (1.6/1.0) solution of chromium (III) acetylacetonate $(5.6 \mathrm{mg} / \mathrm{mL})$ was then added to the precipitates and the reaction mixture was stirred at room temperature for $10 \mathrm{~min}$. A chloroform/pyridine-d mixture (1/1.6) of cyclohexanol ( $35 \mu \mathrm{L}$, $21.5 \mathrm{mg} / \mathrm{mL}$ ) was then added as the internal standard. After the addition of cyclohexanol, $100 \mu \mathrm{L}$ of 2-chloro4,4,5,5-tetramethyl-1,2,3-dioxaphosphine was added as a phosphorylating agent and stirred for $10 \mathrm{~min}$ at room 
temperature. Upon completion, the reaction mixture was analyzed using an INOVA-500 $\mathrm{MHz}$ NMR instrument (Varian, USA).

\section{Results and discussion Wood chip properties}

Table 1 lists the chemical compositions of spruce wood chips. It is seen that the wood chips contained 17.0, $47.2,3.9,2.8$, and $26.5 \mathrm{wt} \%$ of hemicelluloses, cellulose, extractives, acid-soluble lignin, and acid-insoluble lignin, respectively. Similar compositions were reported for spruce wood chips in other reports [31, 32].

\section{Hydrolysis analysis}

Table 2 lists the properties of hydrolysis liquor. The hydrolysis liquor produced in this work had an acidic $\mathrm{pH}$ of 3.2-3.6 implying that the acetyl groups attached to wood chips were partly removed and converted to acetic acid during hydrolysis process $[4,33]$. It is evident that, by increasing temperature, the concentrations of monosugars and hydrolysis lignin were increased while that of polysugars was reduced. The decrease in polysugars content was ascribed to the decomposition of polysugars, which generated more monosugars in the hydrolysis liquor (Table 2) [25]. In another report, the increase in the hydrolysis temperature of poplar from 170 to $190{ }^{\circ} \mathrm{C}$ with a residence time of 60 min slightly increased the removal of monosugars from 2.4 to $4.4 \%$ [33]. The results also showed that the molecular weight of polysugars was slightly reduced by intensifying the process severity. A similar phenomenon was noted by other researchers, which indicated that this reduction could be explained by polysaccharide chains cleavage at elevated temperatures [25] or at prolonged resident times [24]. Interestingly, the furfural content has significantly increased with a temperature rise, which is consistent with the results reported previously [33]. In one study, an increase in the furfural production from the hydrolysis liquor of kraftbased dissolving pulp process was observed via increasing the temperature from 170 to $190{ }^{\circ} \mathrm{C}$ and extending residence time from 20 to $100 \mathrm{~min}$ [34].

The results in Table 2 also show the following: (1) by increasing the temperature at $15 \mathrm{~min}$ hydrolysis time, the concentration of acetic acid increased; (2) by increasing the temperature at $45 \mathrm{~min}$ hydrolysis time, the concentration of acetic acid decreased; and (3) by extending time of hydrolysis from 15 to $45 \mathrm{~min}$, the acetic acid content of hydrolysis liquor was reduced. It is hypothesized that, at a short hydrolysis time of $15 \mathrm{~min}$, more acetyl groups were cleaved by increasing temperature and thus more acetic acid was formed in the hydrolysis liquor [4]. By extending time, or basically providing more severe hydrolysis conditions, the formed acetic acid might have degraded to other products and hence the concentration of acetic acid was reduced (Table 2).

The molecular weight of the lignin in hydrolysis liquor varied between 21,000 and $24,000 \mathrm{~g} / \mathrm{mol}$. It has been found that the molecular weight of milled wood lignin, which was a representative of native lignin for spruce wood [35], was about 23,500 g/mol [36].

The results also showed that, by extending time from 15 to $45 \mathrm{~min}$, there was a slight increase in the concentrations of furfural and monosugars, but a minor decrease in the concentrations of polysugars. It can be claimed that the time extension hydrolyzed (i.e., cleaved) polysugars to monosugars, but the monosugars were subsequently converted to furfural [33]. The concentration of lignin was insignificantly changed via time extension, implying that the hydrolysis conditions were not strong for major lignin removal from wood chips [5].

As discussed earlier, some lignin compounds were generated and precipitated/adsorbed to the digester surface, which were collected via soda liquor treatment. The concentration of soda liquor lignin in soda liquor is also listed in Table 2. No furfural, acetic acid, or sugars were detected in the soda liquor, indicating that these compounds did not adsorb/interact with soda liquor lignin and/or precipitate in the vessel, but were indeed remained in the hydrolysis liquor. It is evident that by increasing the temperature from 170 to $180{ }^{\circ} \mathrm{C}$, more soda liquor lignin was removed from wood chips but the mass of removed soda liquor lignin was slightly reduced at $190{ }^{\circ} \mathrm{C}$. The results in Table 2 show that the molecular weight of soda liquor lignin was around $3000 \mathrm{~g} / \mathrm{mol}$. The molecular weight of soda liquor lignin was lower than that of hydrolysis lignin (Table 2) and that of dioxane lignin or acetic acid-hydrolyzed lignin $(6000 \mathrm{~g} / \mathrm{mol})$ reported elsewhere [37]. The molecular weight of soda liquor lignin was lower at the hydrolysis time of $45 \mathrm{~min}$ (compared to $15 \mathrm{~min}$ ). Generally, by extending time,

Table 1 Chemical compositions of spruce wood chips reported in different reports

\begin{tabular}{llllll}
\hline Hemicellulose, $\mathbf{w t} \%$ & Cellulose, wt\% & Acid-soluble lignin, wt\% & Acid-insoluble lignin, wt\% & Extractives, wt\% & Reference/origin \\
\hline 17.0 & 47.2 & 2.8 & 26.5 & 3.9 & Current work/Canadian \\
18.4 & 45.0 & - & 27.6 & 1.0 & [24]/Danish \\
14.8 & 48.0 & 1.0 & 27.2 & - & [23]/Swedish \\
\hline
\end{tabular}




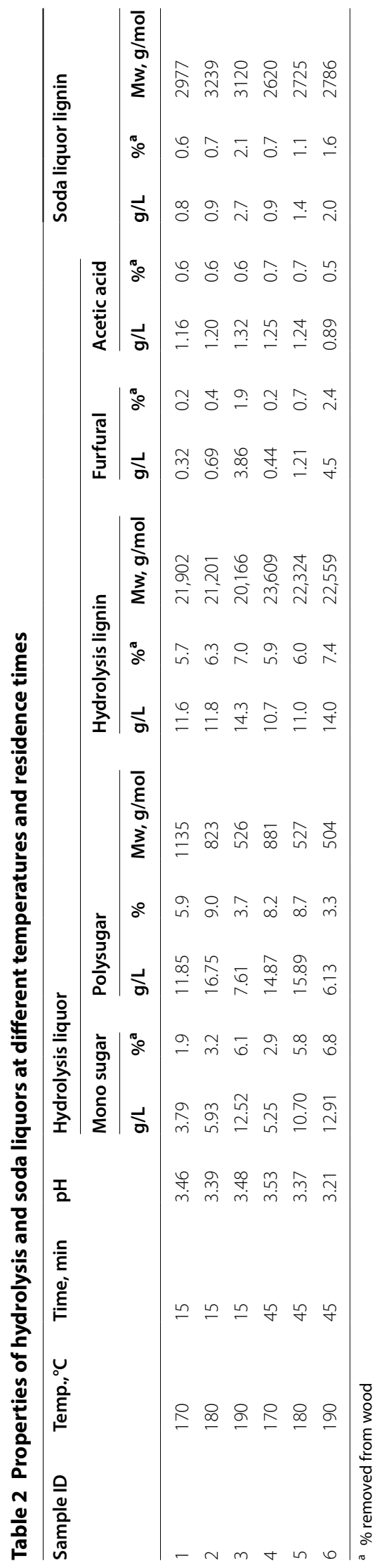


more lignin can be removed from wood chips. The reduction in molecular weight may suggest that the time extension cleaved a part of LCC intermolecular bonds and degraded some carbohydrates. Consequently, the overall molecular weight of lignin presented in soda liquor was reduced. The reduction in the amount of lignin in soda liquor at $190{ }^{\circ} \mathrm{C}$ may provide evidence for this hypothesis.

\section{Acidification of hydrolysis and soda liquors}

Table 3 lists the properties of the hydrolysis and soda liquors after acidification ( $\mathrm{pH}$ 1.5). Comparing the results in Tables 2 and 3 depicts that acidification has insignificantly influenced the concentrations of sugars and hydrolysis lignin, confirming that acidification was ineffective in extracting lignin or sugars from the hydrolysis liquor, and this phenomenon was due to the high solubility of hydrolysis lignin and sugars in acidic solutions. The isolation of sugars in the precipitates made from acidification of hydrolysis liquor produced at $180{ }^{\circ} \mathrm{C}$ and $45 \mathrm{~min}$ was due to the higher concentration of polysugars in hydrolysis liquor under these conditions (Table 2). In another work, the acidification of hydrolysis liquor of kraft-based dissolving pulp production process to $\mathrm{pH} 2$ resulted in a marginal lignin and sugar separation [15], but a drop in the molecular weight of polysugars due to the hydrolysis [38]. A comparison of furfural and acetic acid concentrations before and after acidification (Tables 2,3) shows a drop in their concentrations after acidification, which implies that these compounds were either removed from hydrolysis liquor [12] or degraded via acidification. The results in Table 3 also show that the concentration of soda liquor lignin dropped significantly after adjusting $\mathrm{pH}$ to 1.5 .

Generally, as more lignin and sugar were dissolved in hydrolysis and soda liquors generated at $45 \mathrm{~min}$ of hydrolysis treatment, these samples were selected for further analysis in this work. Table 4 shows the functional groups attached to the precipitates made from acidification of hydrolysis and soda liquors.

Aliphatic hydroxyl $(\mathrm{OH})$, phenolate, and carboxylate groups originally exist in lignin [30,39], and some free phenolate and aliphatic groups would be formed during hydrolysis process $[40,41]$. The formation of $\mathrm{C}-\mathrm{C}$ bonds would occur in the condensation reaction under acidic conditions and contributed to $\mathrm{C}-\mathrm{C}$ bonds (Tables 2, 3) $[42,43]$. Although Table 4 indicates a decrease in C-5 substitution, other carbon-carbon bonds, such as $\beta-\beta$ and $\beta-5$ can be formed in the condensation reaction [44,

Table 3 Properties of acidified hydrolysis liquor and soda liquor

\begin{tabular}{|c|c|c|c|c|c|c|c|c|}
\hline Sample ID & $\begin{array}{l}\text { Mono sugara, } \\
\text { g/L }\end{array}$ & $\begin{array}{l}\text { Poly sugara, } \\
\text { g/L }\end{array}$ & $\begin{array}{l}\text { Hydrolysis } \\
\text { lignin }^{\mathrm{a}}, \mathrm{g} / \mathrm{L}\end{array}$ & Furfural $^{a}, g / L$ & $\begin{array}{l}\text { Acetic acid }{ }^{a}, \\
\text { g/L }\end{array}$ & $\begin{array}{l}\text { Mw of hydrolysis } \\
\text { lignin }^{\mathrm{a}}, \mathrm{g} / \mathrm{mol}\end{array}$ & $\begin{array}{l}\text { Mw of poly } \\
\text { sugar }^{\mathrm{a}}, \mathrm{g} / \mathrm{mol}\end{array}$ & $\begin{array}{l}\text { Soda liquor } \\
\text { lignin }^{b}, g / L\end{array}$ \\
\hline 1 & 3.52 & 12.01 & 11.3 & 0.14 & 0.28 & 24,157 & 804 & 0.4 \\
\hline 2 & 6.9 & 16.84 & 11.0 & 0.32 & 0.5 & 21,484 & 603 & 0.7 \\
\hline 3 & 12.75 & 7.57 & 14.4 & 1.13 & 0.62 & 21,579 & 459 & 1.2 \\
\hline 4 & 5.35 & 14.99 & 10.6 & 0.3 & 0.22 & 23,244 & 578 & 0.7 \\
\hline 5 & 9.33 & 14.62 & 10.9 & 0.46 & 0.52 & 20,713 & 466 & 0.8 \\
\hline 6 & 13.09 & 6.04 & 14.1 & 1.05 & 0.51 & 21,524 & 499 & 1.2 \\
\hline
\end{tabular}

a In hydrolysis liquor

b In soda liquor

Table 4 Functional group associated with precipitates made from the acidification of hydrolysis and soda liquors generated after $\mathbf{4 5} \mathrm{min}$ of the hydrolysis treatment

\begin{tabular}{|c|c|c|c|c|c|c|}
\hline \multirow[t]{2}{*}{ Temperature ${ }^{\circ} \mathrm{C}$} & \multicolumn{3}{|c|}{ Precipitates of hydrolysis liquor $(\mathrm{mmol} / \mathrm{g})$} & \multicolumn{3}{|c|}{ Precipitates of soda liquor $(\mathrm{mmol} / \mathrm{g})$} \\
\hline & 170 & 180 & 190 & 170 & 180 & 190 \\
\hline Aliphatic $\mathrm{OH}$ & 2.04 & 1.54 & 0.75 & 1.05 & 1.14 & 0.53 \\
\hline$C_{5}$ substituted & 0.33 & 0.23 & 0.07 & 0.35 & 0.19 & 0.24 \\
\hline Guaiacyl OH & 1.42 & 1.61 & 0.94 & 1.22 & 1.14 & 0.86 \\
\hline p-Hydroxy phenyl & 0.08 & 0.06 & 0 & 0.1 & 0.03 & 0.02 \\
\hline Carboxylic & 0.14 & 0.14 & 0.06 & 0.71 & 0.67 & 0.53 \\
\hline Total & 4.01 & 3.58 & 1.81 & 3.43 & 3.17 & 2.18 \\
\hline
\end{tabular}


45]. It was reported that the precipitates of hydrolysis liquor made from steam hydrolysis of mixed hardwood contained $1.88 \mathrm{mmol} / \mathrm{g}$ of aliphatic hydroxyl groups, which agrees with that of the present work [41].

It is also evident in Table 4 that increasing the hydrolysis temperature decreased the number of functional groups in the precipitates. The decrease in the contents of the guaiacyl, phenolate, and carboxylate groups in the precipitates (Table 4) is in agreement with the molecular weight decrease at a high temperature shown in Table 2. A previous study claimed that by increasing the temperature, the degradation of carboxylate groups in spruce wood increased [46], which is consistent with the degradation of carboxylate groups in this work when the temperature increased from 170 to $190{ }^{\circ} \mathrm{C}$. The results in Table 4 also depict that the precipitates of soda liquor had generally less aliphatic and guaiacyl hydroxyl, but more C5 substituted, carboxylate, and $p$-hydroxy phenyl groups.

\section{Thermal properties of precipitates from hydrolysis liquor}

The thermal analysis of precipitates was conducted to identify an end-use application for them. The weight loss of precipitates made from the acidification of hydrolysis liquor is shown as a function of temperature in Fig. 2a. It is seen that the weight loss of the precipitates was significant and only $20 \mathrm{wt} \%$ of precipitates were left as char at $700{ }^{\circ} \mathrm{C}$. The weight loss rate of the samples showed a similar decomposition behavior for all samples in the temperature range of $100-700{ }^{\circ} \mathrm{C}$ (Fig. $2 \mathrm{~b}$ ). It has been reported in the literature that the pyrolysis of lignin led to $60 \mathrm{wt} \%$ of char $[47,48]$. It is known that the pyrolysis behavior of materials depends on their compositions and structures [49]. The continuous sharp degradation of precipitates could be attributed to two reasons. (1) The precipitates contained volatile components which gradually evaporated at an increased temperature. As stated above, the concentration of furfural in hydrolysis liquor dropped via acidification and this could indirectly state that furfural precipitated via acidification (Tables 2, 3). The evaporation of furfural from precipitates would be seen as an endothermic effect in thermal analysis and contributed to the weight loss trend observed in Fig. 2. (2) Lignin was degraded in the presence of inorganic compounds at a higher temperature. Sulfuric acid has been reported to enhance the degradation of lignin in pyrolysis [50]. As precipitates were formed via sulfuric acid treatment of hydrolysis liquor, it is possible that some sulfuric acid molecules adsorbed on precipitates and hence contributed to the trend observed in Fig. 2.

To further understand the characteristics of the precipitates, their thermal properties were analyzed by DSC. The heat flow of precipitates produced via acidifying hydrolysis liquor at $170{ }^{\circ} \mathrm{C}$ is shown in Fig. 3. The heating
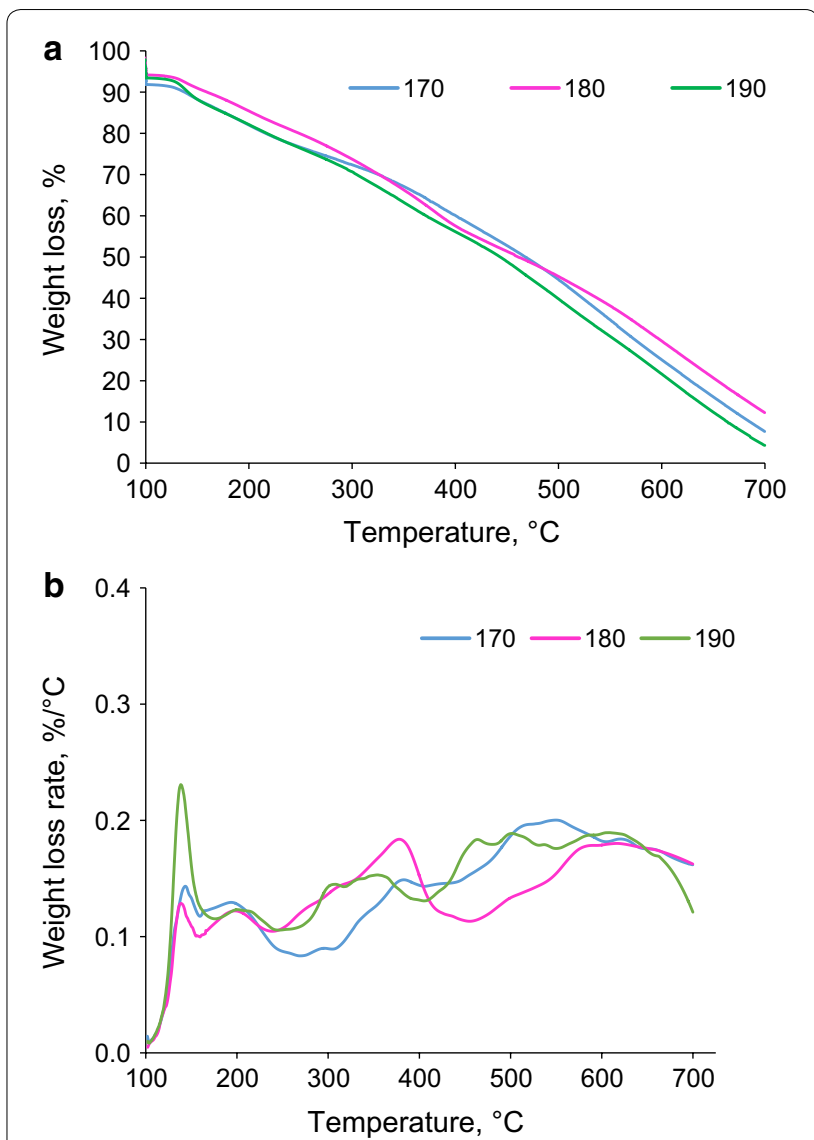

Fig. 2 Weight loss (a) analysis and weight loss rate (b) of precipitates produced via the acidification of hydrolysis liquors generated at 170, 180 , and $190^{\circ} \mathrm{C}$

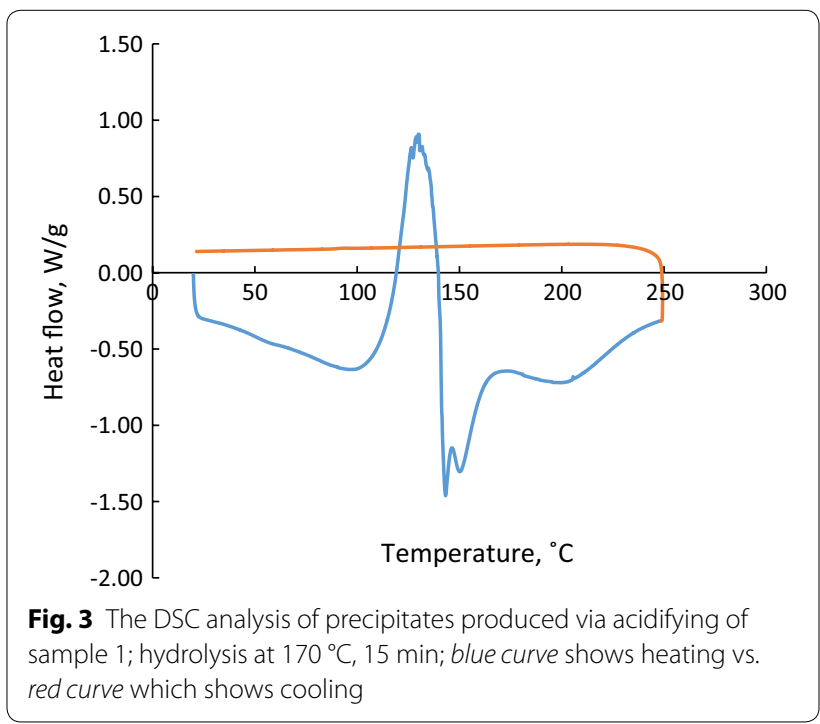

curve peaks are below $200{ }^{\circ} \mathrm{C}$, the boiling temperature of acetic acid is $118{ }^{\circ} \mathrm{C}$, and that of furfural is $161.7^{\circ} \mathrm{C}$ [51]. Therefore, the sharp drop in DSC curves above $150{ }^{\circ} \mathrm{C}$ 
can be explained by furfural evaporation from the precipitates. A similar result was obtained for the DSC analysis of precipitates made from the acidification of hydrolysis liquor generated at 180 or $190{ }^{\circ} \mathrm{C}$ (not shown). It is inferred from Figs. 2 and 3 that precipitates made from the acidification of hydrolysis liquor contained volatile compounds that deteriorated the thermal properties of precipitates in such a way that they were not suitable as bio-fuels.

\section{Thermal properties of unpurified soda liquor lignin}

Figure 4 shows the weight loss and weight loss rate of unpurified soda liquor lignin made from the acidification of soda liquor. It is seen that the first peak occurred at the same position for all the three temperatures, while the second decomposition peak occurred at a higher temperature for the sample prepared at $190{ }^{\circ} \mathrm{C}$ of hydrolysis, indicating that the precipitates would have been more thermally stable if they were produced at a higher temperature in hydrolysis process. Table 4 shows that the total amounts of functional groups are 3.43, 3.17, and $2.18 \mathrm{mmol} / \mathrm{g}$ for precipitates made from hydrolysis at 170,180 , and $190{ }^{\circ} \mathrm{C}$, respectively. In an earlier study, the pyrolysis of wood at a temperature higher than $200{ }^{\circ} \mathrm{C}$ resulted in the degradation of carboxylate groups [46]. Similarly, the present work reveals that the high concentration of functional groups resulted in high mass loss in pyrolysis.

Figure 5 shows the heat flow of precipitates made from the acidification of soda liquor. All precipitates showed a minimum heat flow peak (i.e., melting point) at around $220-230^{\circ} \mathrm{C}$. During the acidification of soda liquor, sulfuric acid reacted with $\mathrm{NaOH}$ present and forms sodium sulfite $\left(\mathrm{Na}_{2} \mathrm{SO}_{3}\right)$ and sodium sulfate $\left(\mathrm{Na}_{2} \mathrm{SO}_{4}\right)$. These salts would also precipitate along with lignin presented in soda liquor.

In order to verify if the endothermic peaks in Fig. 5 (i.e., melting temperature) are due to the melting of the inorganic salts in the precipitates, the heat flows of the pure salts were analyzed as functions of the temperature (Additional file 1). Among $\mathrm{NaOH}, \mathrm{Na}_{2} \mathrm{SO}_{3}$, and $\mathrm{Na}_{2} \mathrm{SO}_{4}$, only $\mathrm{Na}_{2} \mathrm{SO}_{4}$ showed a peak in the heating curve at approximately $240-250{ }^{\circ} \mathrm{C}$. The melting points of $\mathrm{NaOH}$, $\mathrm{Na}_{2} \mathrm{SO}_{3}$, and $\mathrm{Na}_{2} \mathrm{SO}_{4}$ were $318,33.4$, and $884{ }^{\circ} \mathrm{C}$, respectively [50]. An earlier study showed that the endothermic peak at about $250{ }^{\circ} \mathrm{C}$ was due to the changes in the crystalline structure of $\mathrm{Na}_{2} \mathrm{SO}_{4}$ [52]. This confirmed that the peak for $\mathrm{Na}_{2} \mathrm{SO}_{4}$ was a consequence of the changes in the structure of $\mathrm{Na}_{2} \mathrm{SO}_{4}$ present in soda liquor lignin. Therefore, the results confirmed that the heat flow peaks in Fig. 5 were not generated by the organics of precipitates, but they were created by inorganic compounds (i.e., sodium sulfate) present in the precipitates.
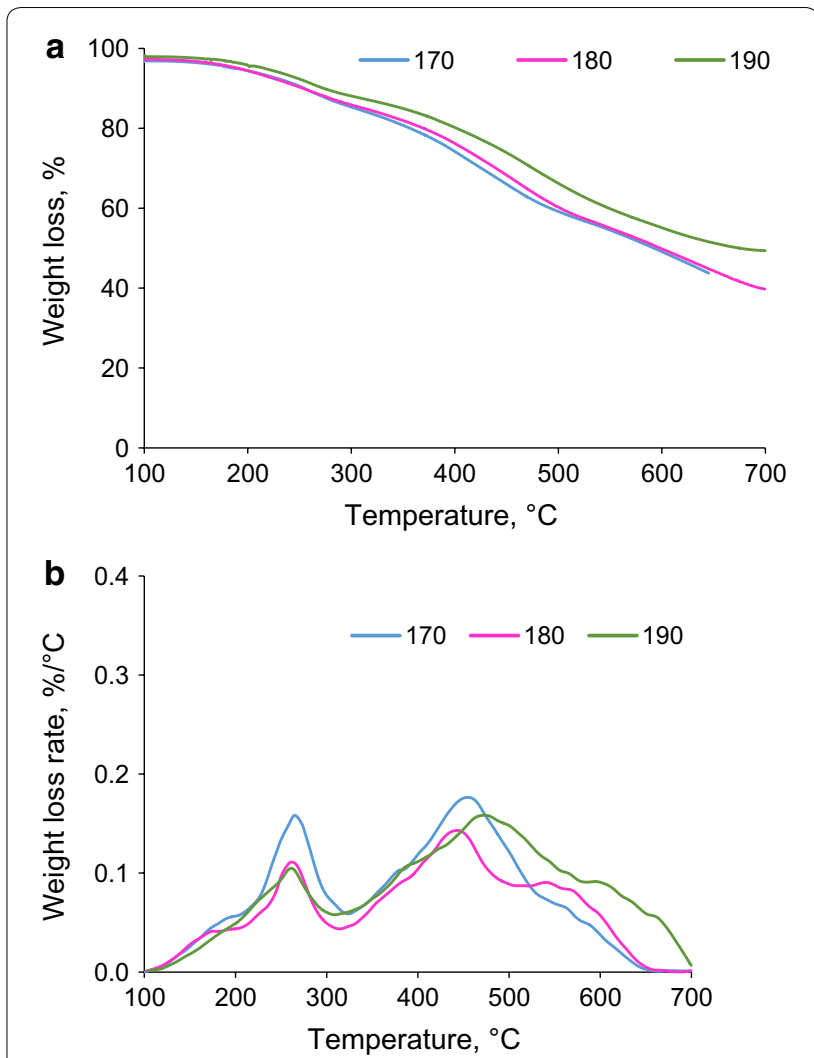

Fig. 4 Weight loss (a) and weight loss rate (b) of unpurified soda liquor lignin of soda liquors collected at different hydrolysis temperatures $\left(170,180\right.$, and $\left.190^{\circ} \mathrm{C}\right)$ but at $45 \mathrm{~min}$

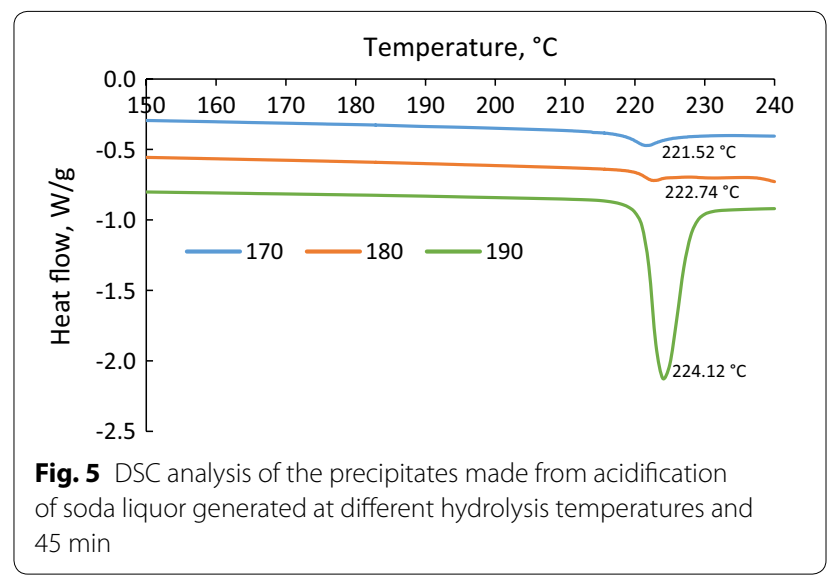

\section{Thermal properties of purified soda liquor lignin}

To remove inorganic salts from soda liquor lignin, the precipitates made from acidification of soda liquor were dialyzed in water with membrane. Figure $6 a$ shows the weight loss of the precipitates after dialysis. It is seen that the pyrolysis of the precipitates resulted in $60 \mathrm{wt} \%$ char, and the precipitates made from hydrolysis at $190{ }^{\circ} \mathrm{C}$ 
generated less char than those made at a lower temperature. It can be seen in Fig. 6b that the samples produced via hydrolysis at 170 and $180{ }^{\circ} \mathrm{C}$ started to decompose at the lower temperature of $200{ }^{\circ} \mathrm{C}$; however, the sample prepared via hydrolysis at $190{ }^{\circ} \mathrm{C}$ decomposed when the temperature was higher than $300{ }^{\circ} \mathrm{C}$. The comparison between the results in Figs. 4 and 6 also depicts that after the pyrolysis, the final char content was higher in the purified precipitates than in the unpurified precipitates. This suggests that membrane dialysis removed some low molecular weight organic compounds in addition to inorganics. Therefore, after pyrolysis of the ash-free lignin, more char was formed.

It is worth noting that the mass loss in Fig. 6 (20-40 $\mathrm{wt} \%)$ is less than the typical mass loss for the pyrolysis of lignin (40-50\%). As discussed earlier, to remove inorganic salts in the dialysis process, some of the small molecular weight compounds might have passed through the membrane. Accordingly, the purified precipitates (i.e., purified soda liquor lignin) had a higher molecular weight, and thus showed higher thermal stability (i.e., less mass loss).
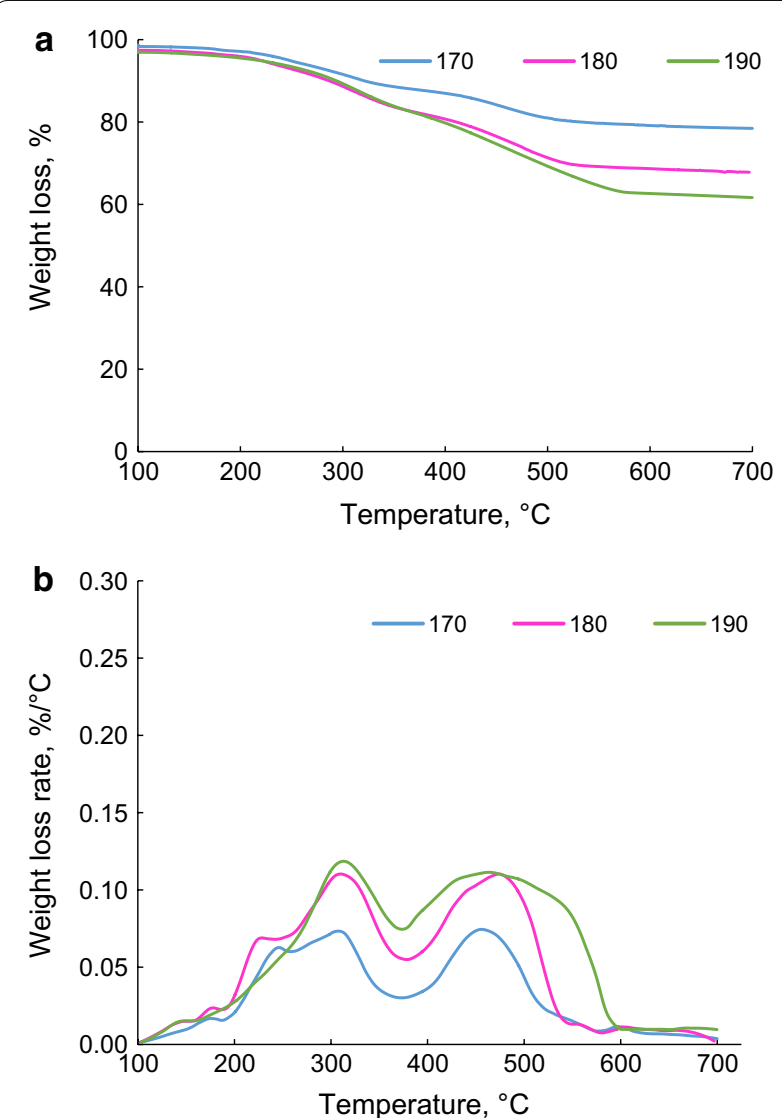

Fig. 6 Weight loss (a) and weight loss rate (b) of purified soda liquor lignin of soda liquor collected at different hydrolysis temperatures $\left(170,180\right.$, and $\left.190^{\circ} \mathrm{C}\right)$ but at $45 \mathrm{~min}$
The heat flow of purified precipitates was also analyzed as a function of temperature (Additional file 1). A peak in the heat flow was observed at $180-190{ }^{\circ} \mathrm{C}$, which suggested that the structure of precipitates changed its state from a glassy state into a rubbery state. The Tg of lignin depends on the processes by which lignin is produced and on the wood source [53]. It has been reported that $\mathrm{Tg}$ of lignin made from acid hydrolysis of softwood was $95{ }^{\circ} \mathrm{C}$, while that of lignin made from steam explosion of softwood was $139{ }^{\circ} \mathrm{C}$ [54]. In another report, the $\mathrm{Tg}$ of lignin made from hot water hydrolysis of hardwood was $170-180{ }^{\circ} \mathrm{C}$ [55]. In this work, increasing the temperature of hydrolysis treatment from 170 to $190{ }^{\circ} \mathrm{C}$ increased the Tg from 184 to $192^{\circ} \mathrm{C}$. This is consistent with an earlier study in which a Tg increase by $8{ }^{\circ} \mathrm{C}$ was reported for increasing the temperature of hot water treatment of hardwood by $20{ }^{\circ} \mathrm{C}$ [55]. Also, heat flow analysis of purified precipitates did not experience any melting point between 200 and $220^{\circ} \mathrm{C}$, which confirms that the melting points in Fig. 4 were indeed due to the presence of inorganic salts in the impure precipitates.

\section{Process development and product applications}

Following the steps shown in Fig. 1, mass balance was developed to identify how much hot water hydrolysis would remove different components from wood chips and the results are listed in Table 5 . It is observable that approximately $25 \%$ of wood chips were isolated via hydrolysis. In the literature, the temperature of $180{ }^{\circ} \mathrm{C}$ and time of $2 \mathrm{~h}$ reported to dissolve more components than a higher temperature and longer time in the hydrolysis process, which support the results presented in Table 5 [56]. The summation of organic compounds in the hydrolysis liquor after acidification, the precipitates of acidification and soda liquor lignin were approximately $95-98 \%$, which shows the high validity of the analysis. The results also depict that acidification of hydrolysis liquor reduced the acetic acid and furfural contents of hydrolysis liquor. Saeed et al. stated that acetic acid and furfural shared $1.31-1.52$ and $0.18-0.31 \%$ of the total solid content of industrially produced hardwood hydrolysis liquor [4]. In the present work, acetic acid and furfural contents of softwood hydrolysis liquor ranged from 0.5 to $0.7 \mathrm{wt} \%$ and from 0.2 to $2.4 \mathrm{wt} \%$ based on the total solid content of hydrolysis liquor, respectively. The discrepancy could be attributed to the differences in the raw materials used in these two studies. Therefore, acidification of hydrolysis liquor (rather than energy intensive evaporation) can be proposed as a method to isolate volatile compounds. However, most polysugars, monosugars, and hydrolysis lignin remained in the solution. Interestingly, the amount of lignin adsorbed on the digester (and 


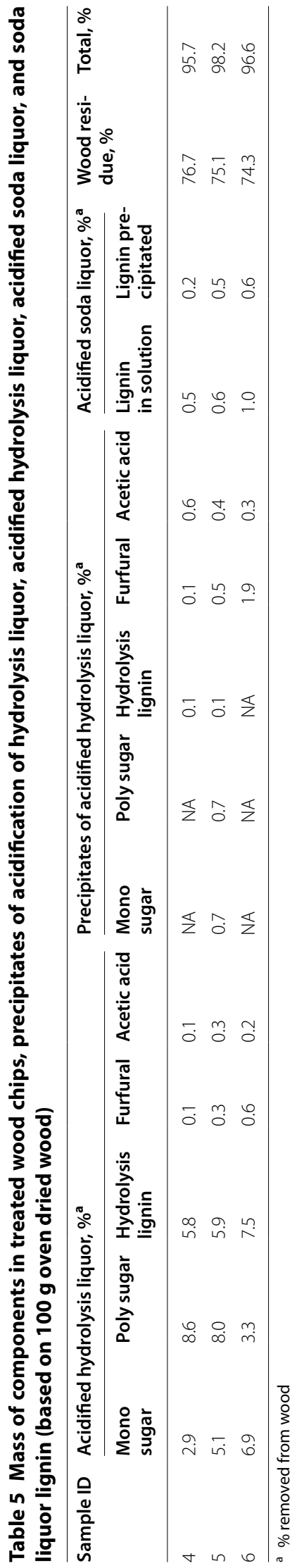


thus removed via soda treatment) was higher than that removed via acidifying hydrolysis liquor.

Figure 7 presents a process for extracting organic materials from hydrolysis liquor. The results in this work show that the hydrolysis of wood chips leads to the extraction of mono and polysugars, furfural, acetic acid as well as lignin from wood chips. As stated earlier, some less soluble lignin compounds were formed and adsorbed on the digester's interior surface. In a large-scale operation, a part of these compounds would be adsorbed on the digester. After saturation of the digester's surface, these compounds would not be able to adsorb on the digester due to the shear stress and pressure applied in the hydrolysis process from feeding/discharging of the digester as well as circulating the hydrolysis liquor in the hydrolysis process as conducted in industry [5]. Therefore, these compounds will be coagulated and form lignin compound flocs. A sedimentation/filtration process could facilitate the precipitation of these lignin flocs from the system. To have purified lignin flocs, the unpurified hydrolysis lignin separated via sedimentation/ filtration can be further washed with acids, e.g., sulfuric acid, and then purified with a membrane. The organics can be isolated from the hydrolysis liquor by heating and acidifying to $\mathrm{pH} 1.5$. Heating is claimed to be a key element in the formation and coagulation of kraft lignin in the LignoForce technology [16]. The results in Tables 2, 3 , and 5 show that the acidification of hydrolysis liquor can be used as means to extract volatile compounds (e.g., furfural and acetic acid) from hydrolysis liquor with precipitates of $2 \%$ based on wood mass (Table 5 ).

Afterward, the acidified hydrolysis liquor can be sent to wastewater treatment. It can then be neutralized and further treated via biological treatment processes [57].
In the developed process shown in Fig. 7, the spent acid that is generated in the purification process of lignin can be used as a source of acid for acidification of hydrolysis liquor. This process is similar to LignoForce in that it uses sedimentation/filtration tank to isolate lignin compounds from hydrolysis liquor and it uses acid washing to further purify the lignin compounds.

The thermal analyses confirm that soda liquor lignin had thermally stable characteristics. Therefore, this product can be used in composite production (e.g.. ligninepoxy resin composites) in which the thermal stability of composite is an advantage [58]. However, more in-depth analysis is required to validate it. In addition, the acidification of hydrolysis liquor made the precipitates that were mainly furfural and acetic acid. These chemicals can be used as platform chemicals for the production of other value-added chemicals, such as plastics, pharmaceutical, and agrochemical industries [59].

As seen in Table 5, it would be possible to produce 1, 5 , and 19 tons of furfural from 1000 tons of wood chips if the procedures for the production of samples 4,5 , and 6 were followed, respectively. Acetic acid would be produced at the rates of 6,4 , and 3 tons if the procedures for the samples 4, 5, and 6 were followed, respectively. It should be stated that this process may not be economical if considered independent as the extraction yield is rather low (Table 5). However, hydrolysis is commercially used as a pretreatment step in the production of dissolving pulp following kraft process and is used for producing wood pellets [4-6]. The proposed process may be economical in these processes, as it may generate additional revenues from a waste resource. However, detailed economic analysis should be conducted to understand the financial feasibility of the proposed process.

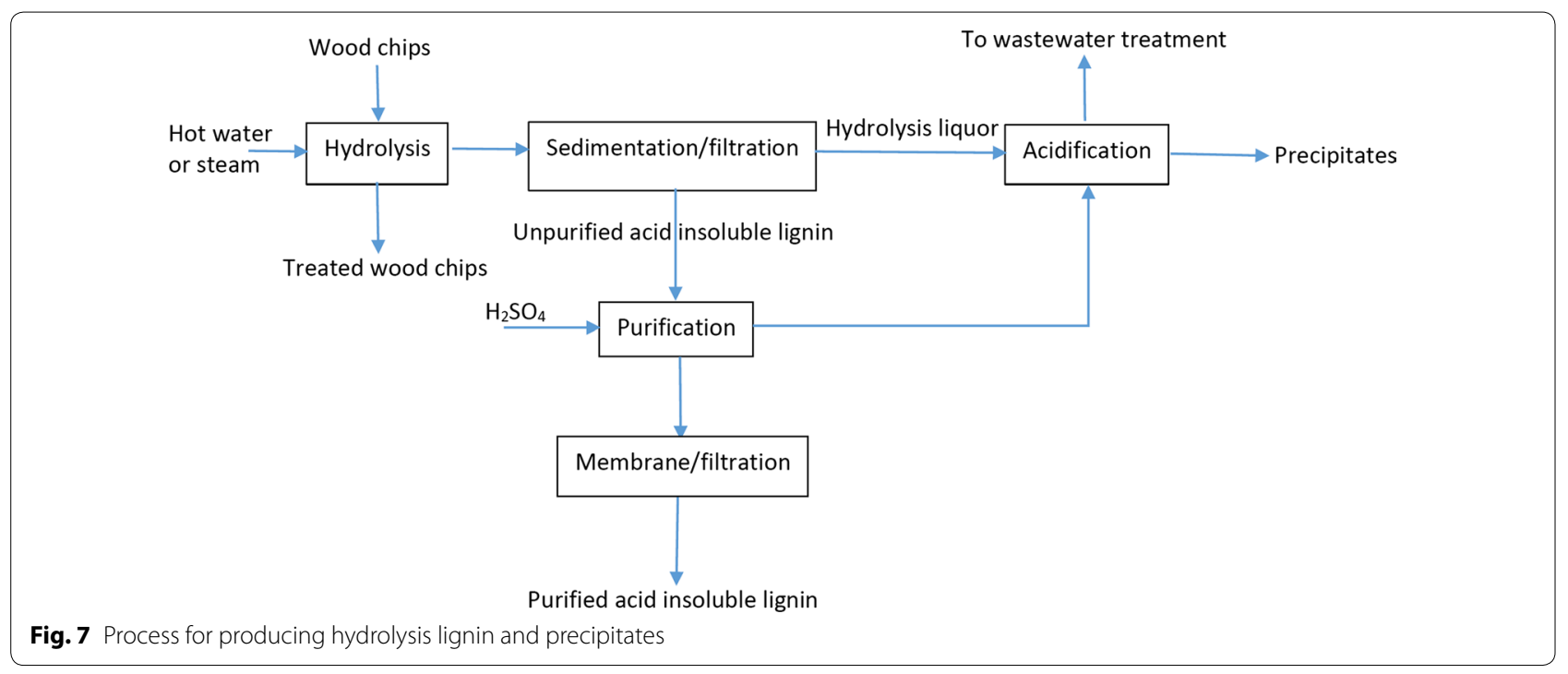




\section{Conclusions}

Processing temperature and residence time showed major effects on the furfural production, but minor effects on sugars and lignin isolations from treated biomass. Increasing the severity of hydrolysis process led to increases in the concentrations of hydrolysis lignin from 11.6 to $14.3 \mathrm{~g} / \mathrm{L}$, monosugars from 3 to $12 \mathrm{~g} / \mathrm{L}$, and furfural from 0.3 to $4 \mathrm{~g} / \mathrm{L}$. However, the concentration of polysugar was the maximum at $180{ }^{\circ} \mathrm{C}$, and more sever conditions reduced its concentration in hydrolysis liquor. The molecular weight of hydrolysis lignin was approximately $22 \mathrm{~kg} / \mathrm{mol}$ and was insignificantly changed under different hydrolysis conditions. The acidification of hydrolysis liquor led to the precipitates that contained mainly furfural and acetic acid rather than hydrolysis lignin and sugars. The concentrations of furfural and acetic acid in hydrolysis liquor were significantly decreased (approximately 31-76\%), but those of lignin and sugars reduced by less than $13 \%$. The acidification of soda liquor led to precipitation of soda liquor lignin (1\% removed from the wood chips) and inorganic impurities. The purified soda liquor lignin showed $\mathrm{Tg}$ around $180-190^{\circ} \mathrm{C}$ and thermal resistance. Based on these results, a process for producing purified lignin and the precipitates of volatile compounds from hydrolysis liquor was developed.

\section{Additional file}

Additional file 1: Figure S1. DSC analysis of a) $\mathrm{NaOH}$, b) $\mathrm{Na}_{2} \mathrm{SO}_{3}$ and c) $\mathrm{Na}_{2} \mathrm{SO}_{4}$ (heating curve is blue). Figure S2. Heat flow of purified precipitates made from soda liquor.

\section{Abbreviations}

DSC: differential scanning calorimetry; LCC: lignin-carbohydrate complexes; L/S: liquid to solid; NMR: nuclear magnetic resonance; TGA: thermogravimetric analysis; TPS: 3-(trimethylsilyl) propionic-2,2,3,3-d 4 acid sodium salt.

\section{Authors' contributions}

TK was the main author of this work and conducted the majority of analysis using the generated data by others. YZ performed DSC analysis. DT carried out the hydrolysis analysis. WG performed the GPC analysis. JP helped with NMR analysis. LH and ND cosupervised TK in this research at Abo Academi and PF was the lead supervisor of the group on this project at Lakehead University. All authors read and approved the final manuscript.

\section{Authors' information}

TK, ND, and LH are associated with laboratory of inorganic chemistry at Abo Academi University in Finland and their research area includes thermal analysis of biomass (e.g. combustion, gasification, and torrefaction). JP is associated with FPInnovations in Canada and her main research interest is the analysis and modification of lignocelluloses. YZ, DT, WG, and PF are researchers at Lakehead University in Canada and their main research areas include the extraction of lignocelluloses from spent liquor and conversion of biomass to value-added products.

\section{Author details}

1 Johan Gadolin Process Chemistry Center, Laboratory of Inorganic Chemistry, Åbo Akademi University, Piispankatu 8, 20500 Turku, Finland. ${ }^{2}$ Chemical Engineering Department, Lakehead University, 955 Oliver Road, Thunder Bay,
ON P7B 5E1, Canada. ${ }^{3}$ Bioeconomy Technology Centre, FPInnovations, 2001 Neebing Ave, Thunder Bay, ON P7E 6S3, Canada.

\section{Acknowledgements}

This work is part of activities at Biomass Utilization Research Laboratory of Lakehead University and the Johan Gadolin Process Chemistry Center, a

Center of Excellence, of Abo Akademi University.

\section{Competing interests}

The authors declare that they have no competing interests.

\section{Availability of supporting data}

The raw data that are related to this work can be available upon requests from the corresponding author.

\section{Funding}

The authors would like to thank (1) Early Researcher Award program of the Government of Ontario, (2) Canada Research Chair and Canadian Foundation for Innovation of the Government of Canada, and (3) Graduate School of Chemical Engineering and Kone foundation at Abo Akademi University for supporting this research. These funding sources were used for covering the costs associated with laboratory analysis of this work at Lakehead University in Canada and with covering travel costs of TK to Canada.

Received: 7 September 2016 Accepted: 9 February 2017

Published online: 23 February 2017

\section{References}

1. Van Heiningen A. Converting a kraft pulp mill into an integrated forest products biorefinery. Pulp Pap Can. 2006;107:38-43.

2. Amidon TE, Liu S. Water-based woody biorefinery. Biotechnol Adv. 2009;27:542-50.

3. Fatehi P, Ni Y. Integrated forest biorefinery-prehydrolysis/dissolving pulping process. In: Zhu J, Zhang X, Pan X, editors. Sustainable production of fuels, chemicals, and fibers from forest biomass, vol 1067. Washington: Amercican Chemical Socitey (ACS) symposium series; 2011. p. 475-506.

4. Saeed A, Jahan MS, Li H, Liu Z, Ni Y, Van Heiningen A. Mass balance of hemicelluloses and other components in the pre-hydrolysis kraft-based dissolving pulp production process. Biomass Bioenergy. 2012;39:14-9.

5. Sixta H. Pulp properties and applications. Handbook of pulp. New York: Wiley; 2006. p. 1009-67.

6. Yan W, Hastings JT, Acharjee TC, Coronella CJ, Vásquez VR. Mass and energy balances of wet torrefaction of lignocellulosic biomass. Energy Fuel. 2010;24:4738-42.

7. Fatehi P, Catalan L, Cave G. Simulation analysis of producing xylitol from hemicelluloses of pre-hydrolysis liquor. Chem Eng Res Des. 2014;92:1563-70

8. Cruz JM, Dominguez JM, Dominguez H, Parajó JC. Solvent extraction of hemicellulosic wood hydrolysates: a procedure useful for obtaining both detoxified fermentation media and polyphenols with antioxidant activity. Food Chem. 1999;67:147-53.

9. Larsson S, Palmqvist E, Hahn-Hägerdal B, Tengborg C, Stenberg K, Zacchi G, Nivebrant N. The generation of fermentation inhibitors during dilute acid hydrolysis of softwood. Enzyme Microb Technol. 1999;24(3-4):151-9.

10. Walton S, Heiningen AV, Walsum PV. Inhibition effects on fermentation of hardwood extracted hemicelluloses by acetic acid and sodium. Bioresour Technol. 2010;101(6):1935-40.

11. Kleinert M, Barth T. Phenols from lignin. Chem Eng Technol. 2008;31:736-45.

12. Liu Z, Fatehi P, Jahan MS, Ni Y. Separation of lignocellulosic materials by combined processes of pre-hydrolysis and ethanol extraction. Bioresour Technol. 2011;102:1264-9.

13. Toledano A, García A, Mondragon I, Labidi J. Lignin separation and fractionation by ultrafiltration. Sep Purif Technol. 2010;71:38-43.

14. Shen J, Kaur I, Baktash MM, He Z, Ni Y. A combined process of activated carbon adsorption, ion exchange resin treatment and membrane concentration for recovery of dissolved organics in pre-hydrolysis liquor of the kraft-based dissolving pulp production process. Bioresour Technol. 2013;127:59-65. 
15. Marques AP, Evtuguin DV, Magina S, Amado FML, Prates A. Structure of lignosulphonates from acidic magnesium-based sulphite pulping of Eucalyptus globulus. J Wood Chem Technol. 2009;29:337-57.

16. Chen X, Wang Z, Fu Y, Li Z, Qin M. Specific lignin precipitation for oligosaccharides recovery from hot water wood extract. Bioresour Technol. 2014;152:31-7.

17. Shi $H$, Fatehi $P$, Xiao H, Ni Y. A combined acidification/PEO flocculation process to improve the lignin removal from the pre-hydrolysis liquor of kraft-based dissolving pulp production process. Bioresour Technol. 2011;102:5177-82.

18. Kouisni L, Holt-Hindle P, Maki K, Paleologou M. The lignoforce system: a new process for the production of high-quality lignin from black liquor. J Sci Technol Prod Proc. 2012;2:6-10.

19. Tomani P. The lignoboost process. Cellul Chem Technol. 2010;44:53-8.

20. García A, Toledano A, Serrano L, Egüés I, González M, Marín F, Labidi J. Characterization of lignins obtained by selective precipitation. Sep Purif Technol. 2009;68:193-8.

21. Fatehi $P$, Gao W, Sun Y, Dashtban M. Acidification of prehydrolysis and spent liquor of neutral sulfite semichemical pulping process. Bioresour Technol. 2016;218:518-25.

22. Toledano A, Serrano L, Garcia A, Mondragon I, Labidi J. Comparative study of lignin fractionation by ultrafiltration and selective precipitation. Chem Eng J. 2010;157:93-9.

23. Grenman H, Eranen K, Krogell J, Willfor S, Salmi T, Murzin D. Kinetics of aqueous extraction of hemicelluloses from spruce in an intensified reactor system. Ind Eng Chem Res. 2011;50:3818-28.

24. Song T, Pranovich A, Sumersky I, Holmbom B. Extraction of galactoglucomannan from spruce wood with pressurised hot water. Holzforschung. 2008;62:659-66.

25. Leppanen K, Spetz P, Pranovich A, Hartonen K, Kitunen V, Ilvesniemi H. Pressurized hot water extraction of Norway spruce hemicelluloses using a flow-through system. Wood Sci Technol. 2011;45:223-36.

26. Song T. Extraction of polymeric galactoglucomannans from spruce wood by pressurised hot water (Academic Dissertation). Turku: Abo Akademi University; 2013.

27. Lawoko M, Henriksson G, Gellerstedt G. Characterization of lignin-carbohydrate complexes (LCCS) of spruce wood (Picea abies L.) isolated with two methods. Holzforschung. 2006;60:156-61.

28. Sluiter A, Hames B, Ruiz R, Scarlata C, Sluiter J, Templeton D, Crocker D. Determination of structural carbohydrates and lignin in biomass. Golden: National Renewable Energy Laboratory (NREL), 2008; TP-510-42618.

29. Tunc MS, van Heiningen AR. Hydrothermal dissolution of mixed southern hardwoods. Holzforschung. 2008;62:539-45.

30. Pu Y, Cao S, Ragauskas AJ. Application of quantitative 31P NMR in biomass lignin and biofuel precursors characterization. Energy Env Sci. 2011:4:3154-66.

31. Mirahmadi K, Kabir MM, Jeihanipour A, Karimi K, Taherzadeh M. Alkaline pretreatment of spruce and birch to improve bioethanol and biogas production. BioRes. 2010;5:928-38.

32. Saleh SB, Hansen BB, Jensen PA, Dam-Johansen K. Influence of biomass chemical properties on torrefaction characteristics. Energy Fuel. 2013;27:7541-8.

33. Li H, Saeed A, Jahan MS, Ni Y, van Heiningen A. Hemicellulose removal from hardwood chips in the pre-hydrolysis step of the kraft-based dissolving pulp production process. J Wood Chem Technol. 2010;30:48-60.

34. Liu $\mathrm{H}, \mathrm{Hu} \mathrm{H}$, Jahan MS, Ni Y. Furfural formation from the pre-hydrolysis liquor of a hardwood kraft-based dissolving pulp production process. Bioresour Technol. 2013;131:315-20.

35. Fujimoto A, Matsumoto Y, Chang H, Meshitsuka G. Quantitative evaluation of milling effects on lignin structure during the isolation process of milled wood lignin. J Wood Sci. 2005;51:89-91.

36. Tolbert A, Akinosho H, Khunsupat R, Naskar AK, Ragauskas AJ. Characterization and analysis of the molecular weight of lignin for biorefining studies. Biofuels Bioprod Biorefin. 2014;8:836-56.

37. Yang G, Jahan MS, Ni Y. Structural characterization of pre-hydrolysis liquor lignin and its comparison with other technical lignins. Curr Org Chem. 2013;17:1589-95.

38. Gurgel LVA, Marabezi K, Zanbom MD, da Silva C. Dilute acid hydrolysis of sugar cane bagasse at high temperatures: a kinetic study of cellulose saccharification and glucose decomposition. Part l: sulfuric acid as the catalyst. Ind Eng Chem Res. 2012;51:1173-85.
39. Guerra A, Filpponen I, Lucia LA, Argyropoulos DS. Comparative evaluation of three lignin isolation protocols for various wood species. J Agric Food Chem. 2006;54:9696-705

40. Evtuguin DV, Neto CP, Silva AM, Domingues PM, Amado FM, Robert D, Faix O. Comprehensive study on the chemical structure of dioxane lignin from plantation Eucalyptus globulus wood. J Agric Food Chem. 2001:49:4252-61.

41. Jahan MS, Liu Z, Wang H, Saeed A, Ni Y. Isolation and characterization of lignin from prehydrolysis liquor of kraft-based dissolving pulp production. Cellul Chem Technol. 2012;46:261-7.

42. Funaoka M, Shibata M, Abe I. Structure and depolymerization of acidcondensed lignin. Holzforschung. 1990;44:357-66.

43. Li J, Henriksson G, Gellerstedt G. Lignin depolymerization/repolymerization and its critical role for delignification of aspen wood by steam explosion. Bioresour Technol. 2007;98:3061-8.

44. Wen J-L, Xue B-L, Sun S-L, Sun R-C. Quantitative structural characterization and thermal properties of birch lignins after auto-catalyzed organosolv pretreatment and enzymatic hydrolysis. J Chem Technol Biotechnol. 2013;88(9):1663-71

45. Guo Y, Zhou J, Wen J, Sun G, Sun Y. Structural transformations of triploid of Populus tomentosa Carr. lignin during auto-catalyzed ethanol organosolv pretreatment. Ind Crops Prod. 2015;76:522-9.

46. Khazraie Shoulaifar T, DeMartini N, Ivaska A, Fardim P, Hupa M. Measuring the concentration of carboxylic acid groups in torrefied spruce wood. Bioresour Technol. 2012;123:338-43.

47. Khazraie Shoulaifar T, DeMartini N, Karlström O, Hupa M. Impact of organically bonded potassium on torrefaction: Part 1. Experimental Fuel. 2016;165:544-52

48. Raveendran K, Ganesh A, Khilar KC. Influence of mineral matter on biomass pyrolysis characteristics. Fuel. 1995;74:1812-22.

49. Fernandes D, Hechenleitner AW, Job A, Radovanocic E, Pineda EG. Thermal and photochemical stability of poly (vinyl alcohol)/modified lignin blends. Polym Degrad Stab. 2006;91:1192-201.

50. Zhou S, Wang Z, Liaw S, Li C, Garcia-Perez M. Effect of sulfuric acid on the pyrolysis of Douglas fir and hybrid poplar wood: Py-GC/MS and TG studies. J Anal Appl Pyrolysis. 2013;104:117-30.

51. Perry RH, Green DW. Perry's chemical engineers' handbook. New York: McGraw-Hill Professional; 1997.

52. Iqbal MZ. Structural, electrical conductivity and dielectric behaviour of $\mathrm{Na}_{2} \mathrm{SO}_{4}$-LDT composite solid electrolyte. J Adv Res. 2016;7:135-41.

53. Tejado A, Pena C, Labidi J, Echeverria J, Mondragon I. Physicochemical characterization of lignins from different sources for use in phenol-formaldehyde resin synthesis. Bioresour Technol. 2007;98:1655-63.

54. Glasser WG, Barnett CA, Muller PC, Sarkanen KV. The chemistry of several novel bioconversion lignins. J Agric Food Chem. 1983;31:921-30.

55. Ko JK, Kim Y, Ximenes E, Ladisch MR. Effect of liquid hot water pretreatment severity on properties of hardwood lignin and enzymatic hydrolysis of cellulose. Biotechnol Bioeng. 2015;112:252-62.

56. Pu Y, Treasure T, Gonzalez R, Venditti RA, Jameel H. Autohydrolysis pretreatment of mixed softwood to produce value prior to combustion. BioEnergy Res. 2013;6(3):1094-103.

57. Rao AG, Bapat AN. Anaerobic treatment of pre-hydrolysate liquor (PHL) from a rayon grade pulp mill: pilot and full-scale experience with UASB reactors. Bioresour Technol. 2006;97(18):2311-20.

58. Yin Q, Yang W, Sun C, Di M. Preparation and properties of lignin-epoxy resin composite. BioRes. 2012;7:5737-48.

59. Eseyina EA, Steele HP. An overview of the applications of furfural and its derivatives. Intl J Adv Chem. 2015;3:42-7. 